\title{
Recognition of Human Insulin In Vitro by T Cells from Subjects Treated with Animal Insulins
}

\author{
Laura J. Nell, Valerie J. Virta, and James W. Thomas \\ Department of Internal Medicine, Baylor College of Medicine, Houston, Texas 77030
}

\begin{abstract}
Structurally defined proteins and peptides have provided considerable information about the specificity and regulation of immune responses in inbred animals. Many diabetics require therapy with insulin; therefore, we used this defined protein as a model antigen to investigate immune responses in the outbred human population. In this report, we examine human $T$ cell recognition of antigenic determinants on various insulins. A group of 25 subjects was selected from over 200 diabetics because of the magnitude of their in vitro responses. 13 of the 25 had significant $T$ cell responses to human insulin despite treatment with only beef/pork insulin mixtures. This autoimmunity may be attributed to crossreactivity of lymphocytes highly reactive to "foreign" epitopes on therapeutic insulins. Alternatively, identical determinants shared by human and animal insulins may be recognized. By employing additional insulins not used therapeutically and isolated A and B chains, several potential mechanisms for lymphocyte autoreactivity to human insulin were demonstrated. Some epitopes are conformational and require recognition of an intact molecule, whereas other epitopes may arise from antigen processing at the cellular level. Studies using zinc-free insulins suggest that zinc-induced alterations of the molecular surface may result in some shared reactivities between animal and human insulin. Furthermore, $T$ cell reactivity against "foreign" epitopes is more complex than anticipated from differences in amino acid sequence. The response patterns of many subjects indicate that the $\mathbf{A}$-chain loop associates with the $\mathbf{N}$-terminal $B$ chain to form a complex determinant. This determinant is recognized more often than individual amino acids. We conclude that insulin therapy generates polyclonal $T$ cell responses directed at multiple epitopes on the molecule. Many of these epitopes are not identified by amino acid exchanges and their presence on human insulin leads to apparent autoimmunity.
\end{abstract}

\section{Introduction}

Insulin is a two-chain globular protein, the molecular structure of which has been extensively characterized. This structure is highly conserved through evolution and the limited amino acid differences in mammalian insulins (Fig. 1) occur at positions that do not alter molecular conformation or affect biologic function (1). The naturally occurring amino acid substitutions are on the surface of the molecule where amino acids that comprise the A-chain loop (A8, A9, A10) are closely associated with the

Received for publication 26 February 1985 and in revised form 24 June 1985.

J. Clin. Invest.

(c) The American Society for Clinical Investigation, Inc.

$0021-9738 / 85 / 12 / 2070 / 08 \$ 1.00$

Volume 76, December 1985, 2070-2077
B-chain terminus $(2,3)$. Two 5,750,000-mol wt insulin monomers form a dimer held together by ionic interactions and, in the presence of $\mathrm{Zn}^{2+}$, dimers assemble into hexamers that interact to form larger aggregates $(2,4)$. These more complex molecular forms are favored by the increased concentrations of insulin found in islets and in therapeutic preparations (U-100 insulin is $4 \mathrm{mg} / \mathrm{ml}$ ) where hexamers are the major molecular form (2). Recently, zinc has been shown to induce alterations in the surface of the insulin molecule that result in the exposure of amino acid side chains that are normally buried in monomer (4). Diabetics treated with insulin, therefore, may be exposed to molecules with alterations owing to zinc-induced changes on the surface or to the approximation in hexamers of residues not associated in the monomer. Either of these alterations may be potential targets of the immune system that is tolerant to circulating insulin monomers.

The majority of insulin-treated diabetics develop antibodies after therapy with animal insulins. Immunologic complications such as allergy and resistance have been documented even with the use of highly purified and human insulin preparations (58). Data from inbred animals show that the immune response to epitopes on insulin is controlled at the cellular level by major histocompatibility complex-linked immune-response genes (911). A recent report of statistical associations between HLA-DR type and responses to therapeutic insulin components supports the concept that similar immune-response genes are present in the outbred human population (12). In those studies, the critical epitopes on the insulin molecule recognized by $\mathrm{T}$ lymphocytes were surmised from amino acid differences between autologous insulin and immunizing insulins. Several recent studies, however, indicate that anti-insulin antibody can be detected in subjects treated only with human insulin preparations $(13,14)$ and in type I diabetics prior to insulin therapy $(15,16)$. In addition, recent studies in mice have shown that both helper and suppressor $T$ cells are primed by insulins presumed to be "nonimmunogenic" $(17,18)$ and suggest that recognition of amino acid exchanges is not the only factor determining insulin immunity. Cellular responses to autologous insulins have not been examined in either inbred animals or human diabetic subjects. In this study, we show that the potential immunogenic epitopes on the insulin molecule are more numerous and complex than anticipated from results with inbred animals. In many cases these epitopes are present on both native and synthetic human insulin preparations. Differences in the amino acid sequence predict only a portion of the antigenic determinants present in insulin.

\section{Methods}

Patients. The subjects used in this study were identified by lymphocyte-proliferative responses to beef and pork insulins. Individuals with reproducible responses of $>5,000 \mathrm{cpm}$ were selected from 200 diabetic outpatients. This level of responsiveness permits discrimination between different antigens and conserves 


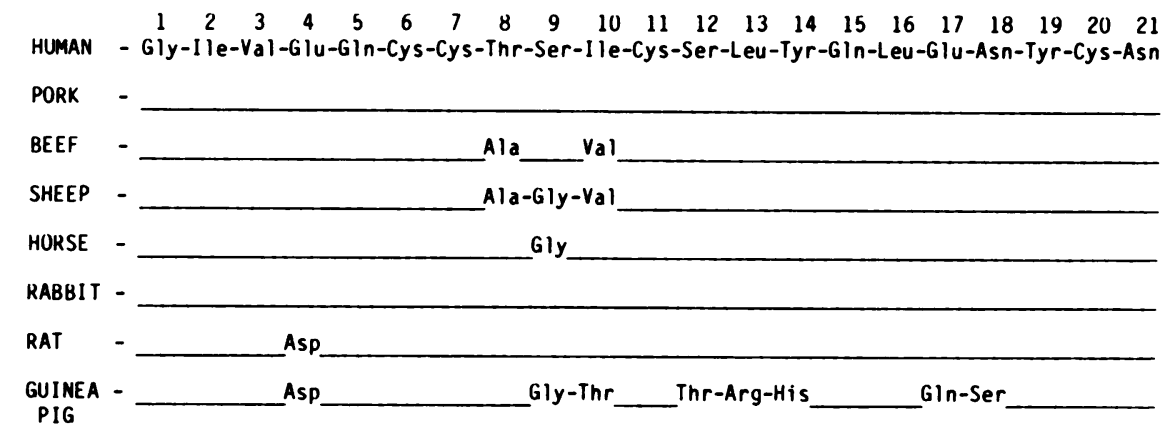

INSULIN B CHAIN

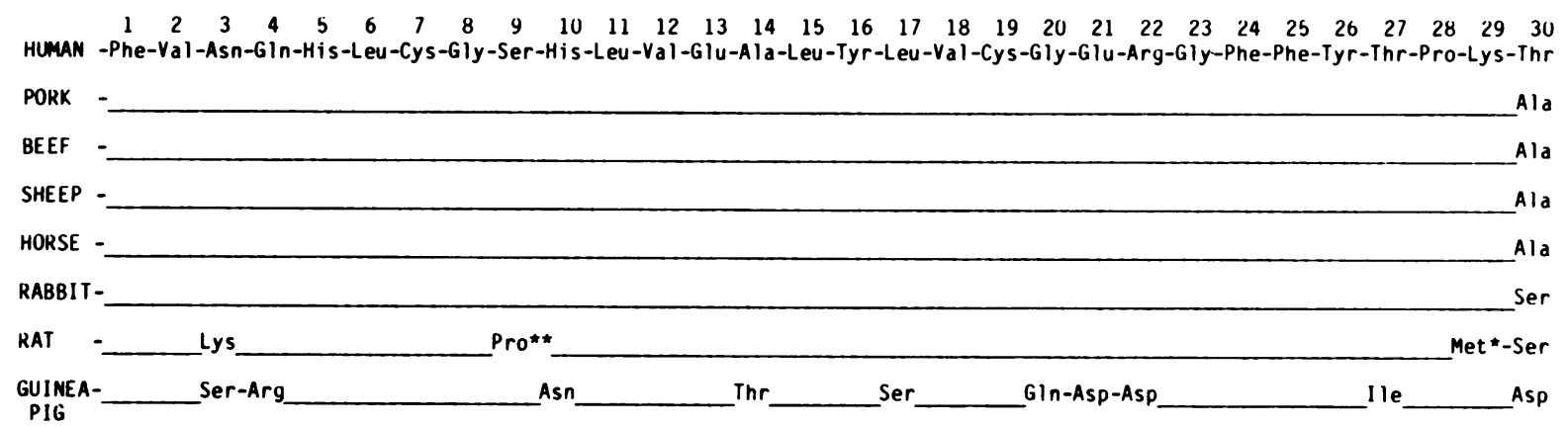

* Present only in Rat 1 .

** Present only in Rat II.

Figure 1. Amino acid sequence differences between human and other mammalian species variants of insulin. The three-letter amino acid abbreviations are used with lines indicating identities. Sequences are from Reference 1.

scarce reagents. Reactivity of this magnitude is present in $\sim 20 \%$ of insulin treated diabetics (19). The 25 subjects ( 13 women, 12 men) were between 24 and $68 \mathrm{yr}$ of age and had been treated with insulin for $2 \mathrm{wk}$ to $18 \mathrm{yr}$ at the onset of the study. All patients had been treated with conventional beef/pork insulin mixtures, and none had received human insulin preparations. The 25 patients presented, as well as $99 \%$ of those studied, all had insulin antibodies when sera were tested in an enzyme linked immunoassay (20). Although variation in antibody levels between individuals was large, the amount and specificity of antibody did not differ between subjects with and without $T$ cell responses. On the basis of disease presentation and other clinical characteristics, nine subjects were felt to have type I (insulindependent) diabetes. These are indicated by $*$ in our figures and tables.

Insulins. Beef, pork, and human insulins for in vitro assays were generously provided by Dr. R. Chance (Lilly Research Laboratories, Indianapolis, IN), or were purchased from Novo Research Institute (Bagsvaerd, Denmark). The lots of insulin used were: Lilly beef, 615-70N-80; Lilly pork, 615-075-256; Lilly biosynthetic human, 615-84S-178-2 and 615-2H2-270-3; Novo monocomponent beef, $\mathrm{O} 8591356$; Novo monocomponent pork, S 8311160; Novo cadaveric human, 800527; and Novo monocomponent semisynthetic human, 6-9-10.2.4. In assays done by the manufacturers, maximum contamination of any of these insulins with proinsulin, glucagon, pancreatic polypeptide, somatostatin, or vasoactive intestinal peptide was $<0.001 \%$. Most were assayed at $<0.01 \mathrm{ppm}$. The Lilly insulins contained $0.6-$ $0.7 \%$ zinc, the Novo insulins $0.38-0.43 \%$ zinc, with comparable amounts of zinc in the beef, pork, and human insulins from each manufacturer. Sheep insulin (lot 71F-0226) and horse insulin (lot 79C-0010) were purchased from Sigma Chemical Co. (St. Louis, MO). Beef and pork sodium insulins were prepared by Dr. Chance and contained no detectible zinc. A and B chain peptides of beef insulin were prepared by Dr. W. Danho and Dr. H.-G. Gattner in the laboratory of Dr. D. Brandenburg (Deutsches Wollforschungsinstitut, Aacken, Federal Republic of Germany) and were the generous gift of Dr. Alan Rosenthal (Merck Institute, Rahway, NJ). These preparations have been described elsewhere (21-23). Briefly, two forms of each chain were employed: those preparations that permitted recombination of disulfide bonds to form loop peptides and those in which the intrachain disulfides were blocked by carboxymethylation. $\mathrm{A}(\mathrm{SS}) \mathrm{SCM}_{2}$ represents $\mathrm{A}$ chain with an intact intrachain disulfide bridge and carboxymethylated interchain disulfide bridges; $\mathrm{A}(\mathrm{SS})_{2}$ represents $A$ chain with two intact disulfide bridges; $\mathrm{B}\left(\mathrm{SS}_{2}\right)$ represents $B$ chain with one intact disulfide bridge; $B(S C M)_{2}$ represents $\mathrm{B}$ chain with carboxymethyl disulfide bridges. Although primary structure has been shown to determine the formation of disulfide bonds (2), the exact manner of disulfide bond formation cannot be proven. For this reason, we used two different preparations of each chain with different degrees of protection of disulfide bonds.

Lymphocyte cultures. Proliferative responses of peripheral blood mononuclear cells were assayed by $\left[{ }^{3} \mathrm{H}\right]$ thymidine $\left(\left[{ }^{3} \mathrm{H}\right] \mathrm{TdR}\right)^{1}$ uptake on day 9 of culture as previously described (19). Briefly, cells were isolated by centrifugation over Isolymph (Gallard-Schlesinger Corp., Carle Place, NY), washed and cul-

1. Abbreviations used in this paper: SI, stimulation index; TdR, thymidine. 
tured at $1 \times 10^{5} /$ well in RPMI containing 5\% human serum (lot 2E009, M.A. Bioproducts, Walkersville, MD) and supplements. Cells were cultured in triplicate with at least three doses of each insulin. Uptake of $\left[{ }^{3} \mathrm{H}\right] \mathrm{TdR}$ by cells during the last $18 \mathrm{~h}$ of culture was determined by scintillation spectroscopy. Data are expressed as the mean counts per minute (cpm) of triplicate cultures with the standard error of the mean. Net responses $(\Delta \mathrm{cpm})$ were calculated by subtracting the mean cpm of unstimulated control cells from the mean cpm of cultures with insulin. Errors of $\Delta \mathrm{cpm}$ were calculated by the formula for propagation of errors. Stimulation indices (SI) were calculated by dividing the mean cpm in response to insulin by the mean cpm in control cultures. SI were rounded off to the nearest whole numbers. We have previously shown that this system assays insulin-immune $T$ lymphocyte responses that are accessory cell-dependent (19).

\section{Results}

Patterns of response to mammalian insulins. Assaying $\left[{ }^{3} \mathrm{H}\right] \mathrm{TdR}$ uptake, we found $\sim 20 \%$ of diabetics develop strong $\mathrm{T}$ lymphocyte-proliferative responses $(>5,000 \mathrm{cpm})$ to beef and pork insulin in vitro. To characterize the fine specificity of these responses, we compared the reactivity to several insulin concentrations using a battery of mammalian insulins. In general, three patterns of lymphocyte recognition can be detected, and these are summarized in Fig. 2. Surprisingly, in some individuals the dose response curve to human insulin was identical to that obtained with animal insulins (Fig. $2 A$ ). Cells from other subjects (Fig. $2 B$ and $C$ ) responded to animal insulins, but the responses were diminished or absent when human insulin was tested. Interestingly, lymphocytes that distinguish the A loop of beef insulin, where there are known amino acid differences from human insulin, were present in only a few subjects ( 4 of 25 ). This recognition was seen only with careful dose response curves (Fig. $2 C$ ). The four subjects in this group were the only patients

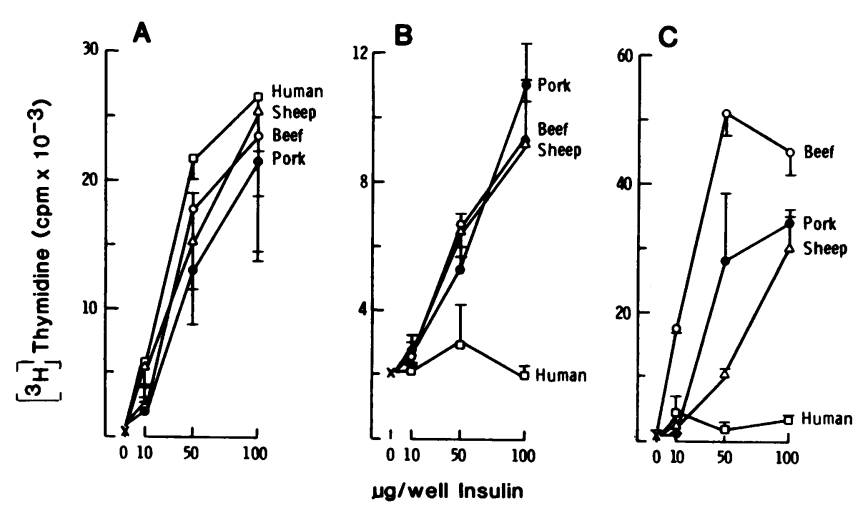

Figure 2. Lymphocyte-proliferative dose-response curves of patients with representative patterns of responses to species variants of insulins. Data are the mean \pm 1 SEM cpm of $\left[{ }^{3} \mathrm{H}\right]$ thymidine taken up by triplicate cultures in response to beef $(0)$, pork $(\bullet)$, sheep $(\Delta)$, and human $(\square)$ insulin versus the concentration of insulin used. The spontaneous background proliferation is also given for each individual $(x)$. $(A)$ Cells from patient S.C., representative of those with equivalent responses to all the insulins, including human. $(B)$ Cells from patient J.H., representative of those responding to animal insulins but not to human insulin. Panel $(C)$ Cells from patient C.T., representative of those responding to animal insulins with a preferentially stronger response to beef insulin.

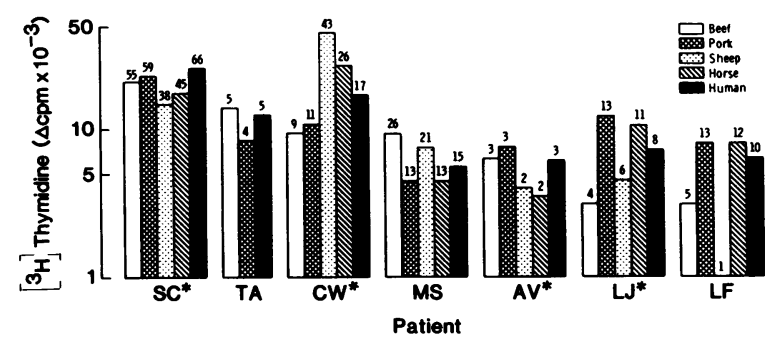

Figure 3. Proliferative responses to human insulin that are as strong as to therapeutic beef and pork insulins. Data are the $\Delta \mathrm{cpm}$ in response to $100 \mu \mathrm{g} /$ well concentrations of beef, pork, sheep, horse, and human insulins with the stimulation index (SI) at the top of each bar. Spontaneous $\left[{ }^{3} \mathrm{H}\right]$ thymidine (mean cpm $\pm \mathrm{SEM}$ ) ranged from $367 \pm 198$ (patient M.S.) to $2,721 \pm 690$ (patient A.V.).

found to respond to low doses of any insulin (10 $\mu \mathrm{g})$, a concentration where the predominant molecular form is the monomer (2). In the following data, these general patterns of response are shown to be more complicated, however this arbitrary division serves as a guide for presentation of the complex data.

Responses in individual patients. The data shown in Figs. 3 and 4 , and Table I summarize the maximal proliferative response and SI of individual patients to multiple insulins. As shown in the representative curves in Fig. 2, cells from the subjects in Figs. 3 and 4 did not respond to low doses of any insulin (10 or $20 \mu \mathrm{g} /$ well). Therefore, only the maximum responses are shown in Figs. 3 and 4. The responses shown in Fig. 3 are from seven subjects whose lymphocyte reactivities to human insulins are as strong as those to animal insulins. These responses were seen

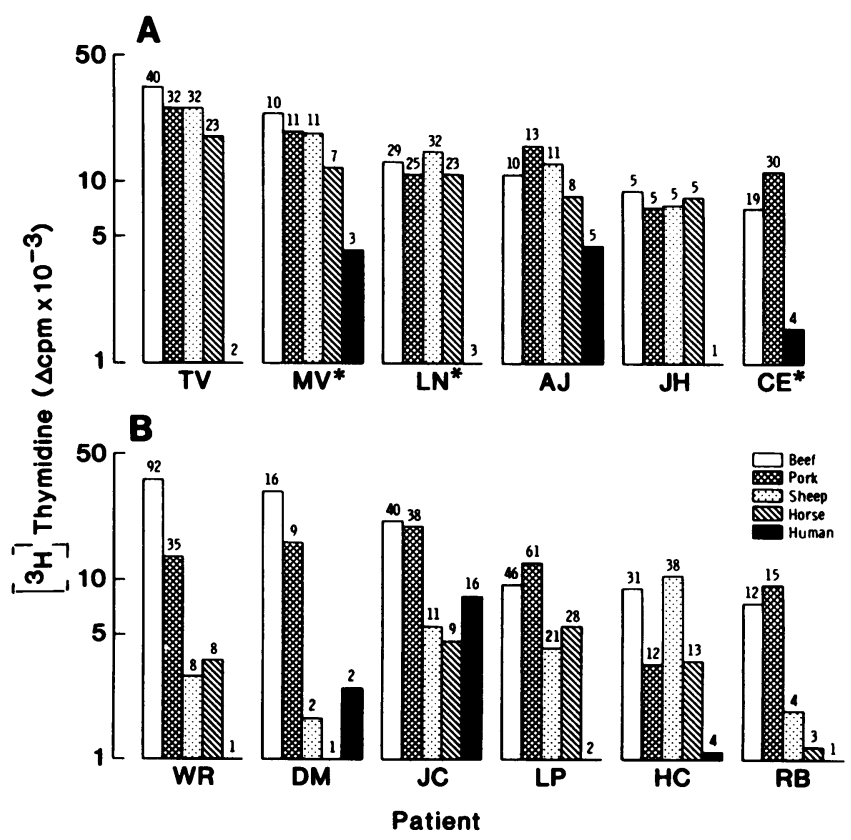

Figure 4. Proliferative responses of cells from individual patients with greater responses to therapeutic beef and pork insulins than to human insulin. Data are as in Fig. 3. $(A)$ Cells from individuals with equal responses to all the ungulate insulins. $(B)$ Cells from patients with stronger responses to therapeutic beef and pork than to nontherapeutic sheep and horse insulins. Spontaneous $\left[{ }^{3} \mathrm{H}\right]$ thymidine uptake (mean cpm \pm SEM ranged from $208 \pm 34$ (patient L.P.) to $2,035 \pm 980$ (patient J.H.). 
Table I. Preferential Responsiveness to Low Doses of Beef Insulin

\begin{tabular}{|c|c|c|c|c|c|}
\hline \multirow[b]{2}{*}{ Patient } & \multirow[b]{2}{*}{ Insulin dose* } & \multicolumn{4}{|c|}{ Proliferative responses to mammalian insulinsł } \\
\hline & & Beef & Pork & Sheep & Human§ \\
\hline \multirow[t]{4}{*}{ T.S. } & 10 & $23,450(8)$ & $9,805(4)$ & $23,714(9)$ & $526(1)$ \\
\hline & 20 & $42,246(15)$ & $14,701(6)$ & $26,573(10)$ & $8,195(4)$ \\
\hline & 50 & $45,464(16)$ & $30,783(11)$ & $41,783(15)$ & $13,212(5)$ \\
\hline & 100 & $73,063(25)$ & $75,087(25)$ & $92,242(31)$ & $28,233(10)$ \\
\hline \multirow[t]{4}{*}{ M.L. } & 10 & $23,328(7)$ & $7,608(3)$ & $17,605(5)$ & $361(1)$ \\
\hline & 20 & $41,429(11)$ & $17,494(5)$ & $17,834(5)$ & $1,772(1)$ \\
\hline & 50 & $54,369(15)$ & $17,879(5)$ & $30,774(10)$ & $10,715(4)$ \\
\hline & 100 & $77,164(20)$ & $37,102(10)$ & $44,541(12)$ & $19,127(6)$ \\
\hline \multirow[t]{4}{*}{ M.K. } & 10 & $15,587(5)$ & $0(1)$ & $2,533(2)$ & $1,404(1)$ \\
\hline & 20 & $15,769(5)$ & $7,760(3)$ & $10,185(4)$ & $5,094(2)$ \\
\hline & 50 & $34,666(11)$ & $17,435(6)$ & $13,580(5)$ & $5,197(2)$ \\
\hline & 100 & $35,493(11)$ & $36,382(11)$ & $31,289(10)$ & $13,380(5)$ \\
\hline \multirow[t]{3}{*}{ C.T. } & 10 & $16,475(18)$ & $326(1)$ & $1,627(3)$ & $3,950(5)$ \\
\hline & 50 & $50,381(54)$ & $27,137(29)$ & $9,269(11)$ & $1,345(2)$ \\
\hline & 100 & $43,943(47)$ & $33,180(36)$ & $28,759(31)$ & $2,008(3)$ \\
\hline
\end{tabular}

* $\mu \mathrm{g}$ insulin/0.2-ml well. $\ddagger$ Data are $\Delta \mathrm{cpm}$ (SI), calculated as described in Methods, in response to insulin from the indicated species. $\S \mathrm{Re}-$ sponses to synthetic human insulin except patient C.T. where responses are to cadaveric human insulin.

with biosynthetic (recombinant DNA), semisynthetic (derived from pork insulin), and pancreatic (cadaver) human insulin preparations. Occasional individual variation that is not easily attributed to known structural changes is noted (e.g., C.W.). These differences suggest that these responses are heterogenous. More than half of this group of subjects (four of seven) had type I diabetes. The data summarized in Fig. 4 show lymphocyte responses with preferential reactivity to animal insulins as compared to human insulin. However, at least 4 of 12 individuals show some reactivity with human insulin. This autoreactivity may represent cross-reactivity of cells that have strong responses to heterologous insulins or it may be due to populations of cells that recognize epitopes similar to those recognized by the subjects in Fig. 3. Previously, in studies that compared reactivities to beef and pork insulins only, responses such as in Fig. $4 A$ were attributed to the B30 terminus where animal insulins differ from human insulin (12). However, some individuals with identical responses to beef and pork insulin have diminished responses when sheep and horse insulins (identical at B30) are used (Fig. $4 \mathrm{~B}$ ). In these subjects both the A loop residues and the $B$ terminus need to be intact for optimal responses. Thus, the epitope(s) recognized may require interaction between several residues rather than being the single amino acid exchange at B30. The close approximation of $\mathrm{B} 30$ with the A loop residues 8,9 , 10 (<10 $\AA)(2,3)$ may allow those areas of the two chains to be recognized as a single epitope on the molecule. Evidence for a similar conformational determinant recognized by mice immune to insulin has been reported (3).

Although we had anticipated that lymphocyte reactivity with the A loop of beef insulin would dominate human responses to insulin, such individuals were unusual (4 of 25). Because this group contains the only subjects with significant responsiveness to the 10- and 20- $\mu \mathrm{g}$ doses of any insulins, all the dose-response curves of these four subjects to animal and human insulins are shown in Table I. At low antigen concentrations (10 and $20 \mu \mathrm{g}$ ) reactivity to A-loop determinants in beef insulin over pork and human is seen with all four subjects. At higher antigen concentrations reactivity with both pork and human insulin can be seen. Only the cells from subject C.T. do not respond at the highest dose of human insulin. Recognition of A-loop residues was found to be heterogeneous; subjects T.S. and M.L. have similar responses to beef and sheep insulins at the $10-\mu \mathrm{g}$ doses but subjects M.K. and C.T. respond poorly to sheep. Thus, the serine present at A9 in beef insulin, but absent in sheep insulin (Fig. 1), is a single amino acid substitution that is potentially recognized by a portion of A-loop responders. The multiple epitopes recognized by lymphocytes from these subjects can not be attributed to prolonged immunization because subjects T.S. and M.L. had only received 2 wk of insulin therapy. No subjects have been identified that respond exclusively to one epitope.

Recognition of isolated $A$ - and B-chain determinants. The above data show that $\mathrm{T}$ cells from many diabetic subjects do not distinguish insulins of different amino acid composition. To further dissect this response, we employed isolated A and B chains to characterize the antigenic determinants on the molecule. The data shown in Fig. 5 summarize experiments comparing lymphocyte responses to equal molar amounts of native insulins and isolated A and B chains of beef insulin. Although of appropriate size, these chain preparations may contain intrachain disulfide linkages not present in the native molecule; therefore, two preparations each of both A and B chains were tested for reactivities. The responses in Fig. $5 \mathrm{~A}$ are those of three individuals whose lymphocytes recognize determinants shared by human and animal insulins. Only one of these subjects has a response to isolated $A$ and $B$ chains. This supports the concept that the response of these individuals, although similar in mag- 


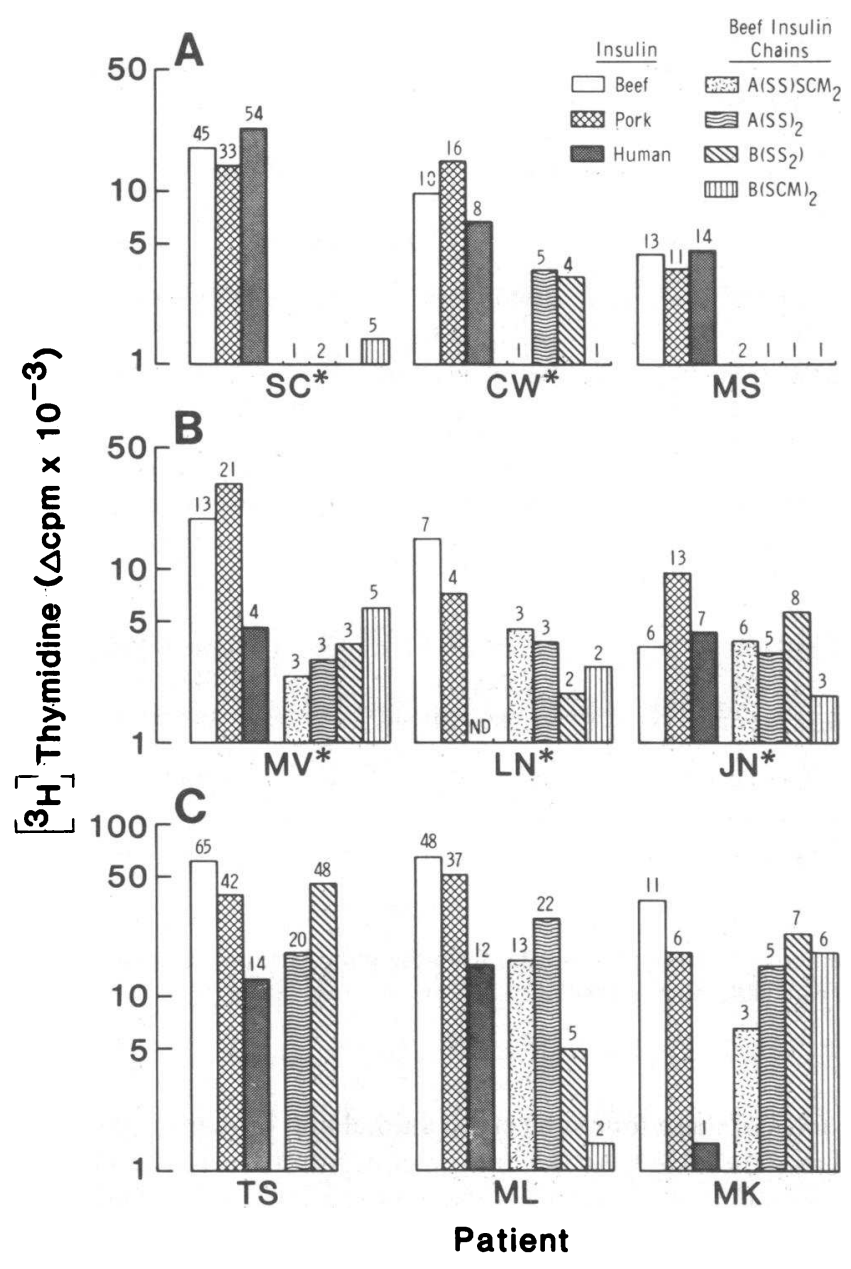

Figure 5. Lymphocyte-proliferative responses of individual patients to $50 \mu \mathrm{g} /$ well of intact beef, pork, and human insulins and to $25 \mu \mathrm{g} /$ well isolated A and B chains from beef insulin. Data are presented as in Fig. 3. (A) Cells from subjects with responses to human insulin as strong as to animal insulins. $(B)$ Cells from subjects with greater responses to therapeutic beef and pork than to human insulin. $(C)$ Cells from subjects with preferentially stronger responses to low doses of beef insulin. Spontaneous $\left[{ }^{3} \mathrm{H}\right]$ thymidine (mean $\mathrm{cpm} \pm \mathrm{SEM}$ ) ranged from $367 \pm 198$ (patient M.S.) to 2,621 \pm 276 (patient L.N.).

nitude, is heterogenous; some require intact native conformation, others do not. Subject C.W. responds only to chain preparations that do not have blocked disulfide bridges, suggesting some conformational limitations to recognition of the isolated chains by his lymphocytes. All other subjects (Fig. $5 B$, those with preferential reactivity to animal over human insulin, and Fig. $5 C$, those with responses to low doses of beef insulin) respond to $A$ and $B$ chains preparations regardless of the presence of carboxymethyl groups used to block cysteines. In Fig. $5 C$, only one of the individuals whose responses were preferential for the A-chain loop of intact beef insulin had a correspondingly greater reactivity to isolated A chain than with B chain (M.L.). Reactivity with B-chain residues, however, further confirms the interpretation that multiple determinants on both chains are recognized by these subjects. These results and those in Table I suggest that the epitopes recognized by human lymphocytes are more complex than some responses noted in inbred animals that appear to be directed at "single residues" $(11,23)$. The weaker responses to isolated chains may be due to differences in the secondary structure between the chain and the native molecule as a result of disulfide bond recombination during chain isolation. The differences however, may also reflect disruption of epitopes that require the approximation of the $\mathrm{A}$ loop and the B-chain terminus. Also, recent studies of antigen processing in animal systems suggest that some $T$ cells only recognize determinants after the antigen has been processed by the macrophage (24-26). Thus, B-chain responses by cells from subjects whose predominant reactivity was directed at the $A$ loop of intact beef insulin (Fig. $5 C$ ) may suggest recognition of epitopes on the antigen-presenting cells in vitro that are not available on the intact molecule but arose through antigen processing at the injection site. Because processed insulin derivatives have not been identified in the circulation (27), these events may be limited to the cells involved locally in the immune response. Such neoantigenic determinants may be clinically important for the induction of helper $T$ cells and may further expand the heterogeneity of the response.

Role of zinc in $T$ cell responses to insulin. In the presence of zinc, insulin forms a variety of complexes and recent studies have shown that this process induces conformation changes on the surface of the molecule (4). These changes, which principally involve the shift of amino acid side chains out to the surface of the molecule, may persist in the monomer. To determine the role of zinc-insulin complexes in $\mathrm{T}$ cell responses, we compared the reactivity to insulins containing zinc with preparations that had zinc removed (sodium insulins). In Table II are data from five individuals comparing responses to several concentrations of sodium and zinc insulins. The presence or absence of zinc does not influence the response of some subjects (M.K. and M.L.), whereas the lymphocyte reactivity to zinc-free insulins is diminished in others (S.C., A.J., L.O.). Thus, epitopes present in zinc-dependent conformations such as hexamers or surface changes induced by zinc may be recognized by immune $T$ cells. Subjects whose $\mathrm{T}$ cells respond equally to human and to animal insulins (S.C. and L.O.) appear to recognize zinc-associated determinants. Because therapeutic insulin preparations contain concentrations that favor the formation of complexes including dimers, hexamers, and larger aggregates (2), all insulin-treated diabetics have been exposed to determinants present on these complexes. Because the zinc-dependent alterations arise at sites not influenced by amino acid sequence variation between species, they could explain some shared reactivities to human and animal insulins. Interestingly, subject M.L. was treated with an insulin preparation that contained increased amounts of zinc (Lente) yet his lymphocyte reactivity was not influenced by the divalent cation.

\section{Discussion}

These studies were initiated to test the hypothesis that cellular reactivity to limited epitopes on the insulin molecule could be used to dissect the immune response in the outbred human population. In contrast to studies of inbred animals, our data indicate that therapy with animal insulin results in polyclonal expansion of $T$ cells that recognize multiple determinants on the molecule, including epitopes on human insulin. The potential antigenic moieties include amino acid exchanges between animal and human insulin, determinants created by the approximation of residues on both chains (e.g., A loop and B-chain terminus), determinants present on isolated $A$ and $B$ chains, and determinants present in zinc-dependent complexes. No individual was iden- 
Table II. Cell Responses to Zinc-containing and Monomeric Zinc-free Sodium Insulin*

\begin{tabular}{|c|c|c|c|c|c|}
\hline \multirow[b]{3}{*}{ Patient } & \multirow[b]{3}{*}{ Insulin doseł } & \multicolumn{4}{|l|}{ Insulin } \\
\hline & & \multicolumn{2}{|l|}{ Pork } & \multicolumn{2}{|l|}{ Beef } \\
\hline & & Zinc & Sodium & Zinc & Sodium \\
\hline \multirow[t]{3}{*}{ M.K. } & 10 & $0(1)$ & $0(1)$ & $15,587(5)$ & $25,622(7)$ \\
\hline & 50 & $17,435(6)$ & $20,696(7)$ & $34,666(11)$ & $27,635(8)$ \\
\hline & 100 & $36,382(11)$ & $43,495(12)$ & $35,493(11)$ & $35,718(10)$ \\
\hline \multirow[t]{3}{*}{ M.L. } & 10 & & & $23,775(7)$ & $25,874(7)$ \\
\hline & 50 & ND§ & ND§ & $54,369(15)$ & $41,621(11)$ \\
\hline & 100 & & & $77,171(20)$ & $37,245(10)$ \\
\hline \multirow[t]{3}{*}{ S.C.* } & 10 & $3,859(3)$ & $515(1)$ & $3,155(3)$ & $1,442(2)$ \\
\hline & 50 & $26,097(13)$ & $1,205(2)$ & $16,251(9)$ & 3,207 (3) \\
\hline & 100 & $23,113(12)$ & $3,156(3)$ & $30,758(15)$ & $3,200(3)$ \\
\hline \multirow[t]{3}{*}{ L.O.* } & 10 & $828(2)$ & $2,235(3)$ & $2,676(4)$ & $2,291(3)$ \\
\hline & 50 & $29,000(30)$ & $2,581(4)$ & $21,917(23)$ & $2,581(4)$ \\
\hline & 100 & $38,274(39)$ & $0(1)$ & $39,754(41)$ & $1,208(2)$ \\
\hline \multirow[t]{3}{*}{ A.J. } & 10 & $2,049(3)$ & $542(1)$ & $424(1)$ & $2,795(3)$ \\
\hline & 50 & $14,206(12)$ & $210(1)$ & $4,481(5)$ & $406(1)$ \\
\hline & 100 & $11,127(10)$ & $1,108(2)$ & $15,900(14)$ & $457(1)$ \\
\hline
\end{tabular}

* Net $\left[{ }^{3} \mathrm{H}\right] \mathrm{TdR}$ uptake in mean counts per minute of triplicate cultures after $9 \mathrm{~d}$ in culture with insulins, expressed as $\Delta \mathrm{cpm}$ (SI). $\ddagger$ Insulin doses in $\mu \mathrm{g} / 0.2-\mathrm{ml}$ well. $\$$ Not determined.

tified whose cellular reactivity was solely directed at a single epitope and half of the subjects had responses directed at epitopes present on both synthetic and pancreatic human insulins.

The autoreactivity against human insulin may develop by several mechanisms. One possibility is that new determinants may arise during antigen processing in vivo. It has been demonstrated that accessory (non-T) cells can take up and degrade antigen by a metabolically active process that requires lysozomal enzymes $(28,29)$. The degraded antigen, potentially in the form of peptides, is then reexpressed on the accessory cell surface in association with Ia antigens for recognition by T cells (26). Studies with several defined proteins (ovalbumin, lysozyme, myoglobin, and cytochrome $c$ ) demonstrate that the epitopes recognized on the accessory cell surface may not be in the native molecule, but rather are a denatured or degraded form (24-26, 28 ). The response to the "denatured" A- and B-chain preparations seen in most subjects (Fig. $5 B$ and $C$ ) may represent recognition of similar denatured determinants that arise from antigen processing of insulin. In addition, the preferential response to zinc insulin (human or animal) over sodium insulin by some subjects may indicate recognition of alterations in the molecule induced by zinc. This hypothesis is also supported by the observation that few subjects respond to low doses of insulin where the monomer is the predominant form. The responses at higher doses in most subjects are consistent with recognition of determinants found on dimers, hexamers, and other zinc-dependent aggregates. In that insulin is stored in islets complexed with zinc (2), it is interesting to speculate that the exposure to such determinants during islet cell destruction may be responsible for the anti-insulin antibodies found in association with the islet cell inflammation of type I diabetes. Because free zinc ions in sufficient concentration are mitogenic for $\mathrm{T}$ cells, an additional adjuvant effect of zinc may also be postulated. In the preparations used, however, zinc is internalized in complexes of insulin. Furthermore, kinetics and ion concentration required for mitogenic responses to free zinc are different than the response to insulin ( 30 and unpublished observations). Antibody studies also support the concept that immunoreactive determinants on the molecules are present in zinc-dependent conformations $(31,32)$. In studies with insulin antisera not only was zinc-free insulin shown to have marked decreased immunologic activity at concentrations where insulin was thought to be monomeric (31), but it was also shown that addition of zinc restored immunologic activity (32). Recognition of similar zinc-dependent immunogenic determinants by human lymphocytes is one potential explanation for the extensive cross-reactivity between human and animal insulins.

In addition to alterations of the insulin molecule to produce "neoantigenic" determinants, some of the reactivities with human insulin may be explained on the basis of cross-reactivities at high concentrations of antigen. This assay system does not permit us to distinguish cross-reactions from the combined responses of several clones. However, one subject with beef-preferential responses did not show reactivity to the highest concentration of human insulin (C.T., Table I), indicating that crossreactivity of beef insulin-specific $T$ cells will not always be seen with human insulin. This is further supported by the other subjects in Fig. 4 who also respond to animal insulins without reacting to human insulin. More important, autoimmunity to human insulin may stem from recognition of "self" epitopes by cells that escape normal immune regulation or tolerance mechanisms (18). Whereas this possibility is not easily tested using species variants of insulin, some subjects were noted to require the serine at position A9 for optimal responses to low doses of beef insulin. This residue is also present in human insulin. The hydroxyl group of this serine has been shown to contribute to 
immunogenic determinants recognized by some mice (33), and may also be recognized by autoreactive $\mathrm{T}$ cells in humans. Similar epitopes may be involved in the complex cellular regulation recently shown in mice to control helper $T$ cell generation for insulin (18). These studies have recently been expanded to demonstrate that murine helper $\mathrm{T}$ cells can be generated with autologous insulin (Jensen, P. E., and J. A. Kapp, manuscript submitted for publication). This autoimmunity was detected when immunoregulatory circuits were removed. Likewise, our studies indicate the complexity of the human immune response to insulin may be enormous, and treatment with heterologous insulin may predispose to a more complex response by circumventing normal regulatory events. Similar studies carried out on individuals treated only with human insulin would help contrast the response with heterologous insulin and establish the role of both processed antigenic determinants and zinc-induced changes in immunogenicity. The detection of anti-insulin antibodies in subjects treated only with human insulin $(13,14)$ suggests that helper $T$ cells recognizing human insulin can develop without the use of animal insulins.

Our preliminary attempts to use serological HLA detection to study the genetic contributions to these responses were disappointing. Three subjects with the strongest responses to beef insulin all had different DR types, and none had DR4 that was previously reported to be statistically associated with the beef response (12). Although serologic typing may identify statistical associations with responsiveness in population studies, they are not predictive in individuals. In view of the multiple epitopes involved in the $\mathrm{T}$ cell responses, the racial mixture of our study population, and the complexity of human Ia antigens, we cannot justify the expense of serologic typing as a means to identify genetic contributions to the response. Rather, our current approach is to develop $T$ cell lines reactive with individual epitopes. This will enable us to determine whether differences in the magnitude of responses are due to different frequencies of responding cells or to cross-reactivities of cells for different epitopes. Cell lines can be used to determine the role of antigen processing in the human $T$ cell response to insulin. These lines can then be used to determine whether restriction elements for different epitopes are shared between individuals and may help identify important mechanisms that regulate the immune response to insulin in humans.

\section{Acknowledgments}

The authors wish to thank Drs. Geraldine Miller and Donald M. Marcus for critically reviewing the manuscript and for useful discussions of the data and Dr. Marilyn S. Pollack for doing HLA typing. We also wish to thank Dr. Judith Kapp for sharing her data on murine studies with us. We also acknowledge the assistance of our colleagues in obtaining patient samples: Dr. John P. Comstock, Dr. Julie A. Ellerhorst, Dr. Alton S. Steiner, and the Faculty and Staff of The University of Texas at Houston Diabetes Center. We also thank Charlene Shackelford for her enthusiastic aid in the preparation of this manuscript.

These studies were supported in part by grants AM-32329 and AI-21289 from the National Institute of Health and by the Juvenile Diabetes Foundation.

\section{References}

1. Wojciech, R., and E. Margoliash. 1968. Amino acid sequences of proteins-hormones. In CRC Handbook of Biochemistry. Selected Data for Molecular Biology. The Chemical Rubber Co., Cleveland. C-185.
2. Blundell, T., G. Dodson, D. Hodgkin, and D. Mercola. 1972. Insulin: the structure in the crystal and its reflection in chemistry and biology. Adv. Protein Chem. 26:279-402.

3. Glimcher, L. H., J. A. Schroer, C. Chan, and E. M. Shevach. 1983. Fine specificity of cloned insulin-specific $\mathrm{T}$ cell hybridomas: evidence supporting a role for tertiary conformation. J. Immunol. 131:2867-2873.

4. Chothia, C., A. M. Lesk, G. G. Dodson, and D. C. Hodgkin. 1983. Transmission of conformational change in insulin. Nature (Lond.). 302: 500-505.

5. Grammer, L. C., P. Y. Chen, and R. Patterson. 1983. Evaluation and management of insulin allergy. J. Allergy Clin. Immunol. 71:250254.

6. Altman, J. J., M. Pehuet, G. Slama, and C. Tchobroutsky. 1983. Three cases of allergic reaction to human insulin. Lancet. ii:524.

7. Berke, L., J. A. Owen, and R. L. Atkinson. 1984. Allergies to human insulin. Diabetes Care. 7:402-403.

8. Ross, J. M., M. R. Murali, T. C. DeLara, and R. G. Cheron. 1984. Anaphylaxis and immunologic insulin resistance in a diabetic woman with ketoacidosis. Diabetes Care. 7:276-279.

9. Keck, K. 1975. Ir gene control of carrier recognition. I. Immunogenicity of bovine insulin derivatives. Eur. J. Immunol. 5:801-807.

10. Rosenthal, A. S., M. A. Barcinski, and J. T. Blake. 1977. Determinant selection is a macrophage mediated immune response gene function. Nature (Lond.). 267:156-158.

11. Rosenwasser, L. J., M. A. Barcinski, R. H. Schwartz, and A. S. Rosenthal. 1979. Immune response gene control of determinant selection. II. Genetic control of the murine T lymphocyte proliferative response to insulin. J. Immunol. 123:471-476.

12. Mann, D. L., N. Mendell, C. R. Kahn, A. H. Johnson, and A. Rosenthal. 1983. In vitro lymphocyte proliferation response to therapeutic insulin components. Evidence for genetic control by the human major histocompatibility complex. J. Clin. Invest. 72:1130-1138.

13. Fineberg, S. E., J. A. Galloway, N. S. Fineberg, M. J. Rathbun, and S. Hufferd. 1983. Immunogenicity of recombinant DNA human insulin. Diabetologia. 25:465-469.

14. Heding, L. G., M. O. Marshall, B. Persson, G. Dahlquist, B. Thalme, F. Lindgren, H. K. Akerblom, A. Rilva, M. Knip, J. Ludvigsson, L. Stenhammar, L. Stromberg, O. Sovik, H. Baevre, K. Wefrig, J. Vidnes, J. J. Kjaergard, P. Bro, and P. H. Kaad. 1984. Immunogenicity of monocomponent human and porcine insulin in newly diagnosed type 1 (insulin-dependent) diabetic children. Diabetologia. 27:96-98.

15. Palmer, J. P., C. A. Asplin, P. Clemons, K. Lyen, O. Tatpati, P. K. Raghu, and T. L. Paquette. 1983. Insulin antibodies in insulindependent diabetics before insulin treatment. Science (Wash. DC). 222: 1337-1339.

16. Wilkin, T., M. Armitage, C. Casey, D. A. Pyke, P. J. Hoskins, M. Rodier, J.-L. Diaz, and R. D. G. Leslie. 1985. Value of insulin autoantibodies as serum markers for insulin-dependent diabetes mellitus. Lancet. i:480-482.

17. Bucy, R. P., and J. A. Kapp. 1981. Ir gene control of the immune response to insulins. I. Pork insulin stimulates $\mathrm{T}$ cell activity in nonresponder mice. J. Immunol. 126:603-607.

18. Jensen, P. E., C. W. Pierce, and J. A. Kapp. 1984. Regulatory mechanism in immune responses to heterologous insulins. II. Suppressor $\mathrm{T}$ cell activation associated with nonresponsiveness in H-2 ${ }^{\mathrm{b}}$ mice. J. Exp. Med. 160:1012-1016.

19. Nell, L. J., and J. W. Thomas. 1983. The human immune response to insulin. I. Kinetic and cellular aspects of lymphocyte proliferative responses in diabetics. J. Immunol. 131:701-705.

20. Nell, L. J., V. J. Virta, and J. W. Thomas. 1985. Application of a rapid enzyme-linked immunosorbent microassay (ELISA) to study human anti-insulin antibody. Diabetes. 34:60-66.

21. Touber, J. L., R. W. Stoll, J. W. Ensinck, and R. H. Williams. 1970. Immunological studies of the A and B chains of insulin Diabetes. 19:409-419.

22. Blackard, W. G. 1967. Radioimmunoassay of the A-chain of insulin. Diabetes. 16:681-686.

23. Thomas, J. W., W. Danho, E. Bullesbach, J. Fohles, and A. S. 
Rosenthal. 1981. Immune response gene control of determinant selection. III. Polypeptide fragments of insulin are differentially recognized by $T$ but not by B cells in insulin immune guinea pigs. J. Immunol. 126:10951100 .

24. Streicher, H. Z., I. J. Berkower, M. Busch, F. R. N. Gurd, and J. A. Berzofsky. 1984. Antigen conformation determines processing requirements for T-cell activation. Proc. Natl. Acad. Sci. USA. 81:68316835.

25. Kovac, Z., and R. H. Schwartz. 1985. The molecular basis of the requirement for antigen processing of pigeon cytochrome $\mathrm{c}$ prior to $\mathrm{T}$ cell activation. J. Immunol. 134:3233-3240.

26. Shimonkevitz, R., J. Kappler, P. Marrack, and H. Grey. 1983. Antigen recognition by H-2-restricted $\mathrm{T}$ cells. I. Cell-free antigen processing. J. Exp. Med. 158:303-316.

27. Sodoyez, J. C., F. R. Sodoyez-Goffaux, and Y. M. Moris. 1980. ${ }^{125}$ I-insulin: Kinetics of interaction with its receptors and rate of degredation in vivo. Am. J. Physiol. 239(Endocrinol. Metab. 2):E3-E11.

28. Allen, P. M., and E. R. Unanue. 1984. Differential requirements for antigen processing by macrophages for lysozyme specific $\mathrm{T}$ cell hybridomas. J. Immunol. 132:1077-1079.

29. Chesnut, R. W., S. M. Colon, and H. M. Grey. 1982. Requirements for the processing of antigens by antigen-presenting $B$ cells. I. Functional comparison of B cell tumors and macrophages. J. Immunol. 129:2382-2388.

30. Berger, N. A., and A. M. Skinner. 1974. Characterization of lymphocyte transformation induced by zinc ions. J. Cell Biol. 61:4555.

31. Arquilla, E. R., P. Thiene, T. Brugman, W. Ruess, and R. Sugiyama. 1978. Effects of zinc ion on the conformation of antigenic determinants on insulin. Biochem. J. 175:289-297.

32. Hamlin, J. L., and E. R. Arquilla. 1974. Monoiodoinsulin. Preparation purification, and characterization of a biologically active derivative substituted predominantly on tyrosine A14. J. Biol. Chem. 249:21-32.

33. Talmon, J., G. Ranghino, A. Yonath, and I. R. Cohen. 1983. Structural analysis of insulin determinants seen by $T$ cells directed by H-2 genes. Immunogenetics. 18:79-89. 